\title{
Custos e viabilidade da implantação de uma unidade armazenadora de grãos no Mato Grosso
}

Costs and feasibility of the implantation of a grain storage unit in Mato Grosso

\author{
Rafael Antonio Vieira ${ }^{1}$; Flávio Carlos Dalchiavon²*
}

${ }^{1}$ Engenheiro Agrícola - Rua Haroldo Veloso no 327 - Jardim Boa Esperança - 68181-020 - Itaituba, PA - Brasil

${ }^{2 *}$ Engenheiro Agrônomo, Doutor em Agronomia, Instituto Federal de Educação, Ciência e Tecnologia de Mato Grosso, Campus Campo Novo do Parecis, Rodovia MT 235, km 12, s/n, Caixa Postal n 100, Zona Rural - 78360000 - Campo Novo do Parecis, MT - Brasil <flavio.dalchiavon@cnp.ifmt.edu.br>

\section{Resumo}

A capacidade de armazenagem no Brasil, infraestrutura que exige elevadas somas de investimentos não tem acompanhado o ritmo de crescimento das safras ao longo dos anos. Sendo assim, objetivou-se avaliar os custos e a viabilidade da implantação de uma unidade armazenadora de grãos na cidade de Sorriso no estado do Mato Grosso no ano de 2017. Para o dimensionamento da unidade foi considerada a capacidade máxima de colheita de uma fazenda que possui 1500 hectares disponíveis para a semeadura de soja e milho. No cálculo de viabilidade econômica foram utilizados parâmetros como a taxa interna de retorno, ponto de equilíbrio econômico, valor presente líquido e "payback" do investimento. Os resultados obtidos para o investimento de uma infraestrutura capaz de processar a produção desta fazenda levam a uma estimativa de custo de aproximadamente $\mathrm{R} \$$ 4.035.754,00, sendo feito por financiamento de 100\%, através da linha de crédito Programa para Construção e Ampliação de Armazéns [PCA], a 8,5\% de juros ao ano, ao longo de dez anos. O empreendimento obtém receitas anuais de $\mathrm{R} \$ 1.144 .042,20$ e custos totais anuais de $\mathrm{R} \$$ $525.137,00$, um valor presente líquido de $\mathrm{R} \$ 25.090,99$ e uma taxa interna de retorno de 6,98\%, o ponto de equilíbrio foi de $\mathrm{R} \$ 356.224,72$ e o prazo de retorno do investimento de dez anos, mostrando que a implantação deste empreendimento pode ser uma opção viável econômica e financeiramente.

Palavras-chave: agronegócio, estocagem de grãos, indicadores financeiros, viabilidade econômica

\begin{abstract}
In Brazil, storage capacity, an infrastructure that requires large sums of investment, has not kept pace with the growth of the crops over the years. As a result, the objective of this study was to evaluate the costs and feasibility of the implantation of a grain storage unit in the city of Sorriso, State of Mato Grosso in 2017. For the sizing of the unit, the maximum harvest capacity of a farm with 1500 hectares available for the planting of soybean and corn was considered. In relation to the calculation of economic viability, the parameters such as internal rate of return, economic break-even point, net present value and investment payback were used. The results obtained for the investment of an infrastructure capable of processing the production of this farm leads to a cost estimate of approximately R $\$ 4,035,754.00$, made by 100\% financing through a credit line granted by Programa para Construção e Ampliação de Armazéns [PCA] (Construction and Warehouse Extension Program) at an interest rate of $8.5 \%$ per year over ten years. The results found for the enterprise were, as follows: annual revenues of $\mathrm{R} \$ 1,144,500.00$; total annual costs of $\mathrm{R} \$ 525,137.00$; net present value of $\mathrm{R} \$ 25,090.99$; internal rate of return of $6.98 \%$; break-even point of $\mathrm{R} \$ 356,224.72$ and the term of return on the investment was ten years, showing that the implementation of this venture may be an economically and financially viable option.
\end{abstract}

Keywords: agribusiness, storage of grain, financial indicators, economic viability

\section{Introdução}

A atividade agrícola vem sendo aperfeiçoada para minimizar os custos, gerando uma melhora na produtividade brasileira. Nos últimos anos, novos serviços desde estrutura física a formas de gestão estão sendo implementados por produtores, pois é necessário tornar-se competitivo e reduzir os custos. Armazenagem de grãos inclui todo o processo necessário para manter estoques guardados e protegidos de forma adequada, mantendo as qualidades biológicas, químicas e físicas desses produtos imediatamente após a colheita. Considera-se como parte do processo de armazenagem, a recepção, descarga, carregamento e organização do estoque (Dambrosio et al., 2009).

A capacidade de armazenagem no Brasil, infraestrutura que exige elevadas somas de investimentos, não tem acompanhado o ritmo de crescimento das safras ao longo dos anos, verificando-se déficit em determinadas regiões, principalmente naquelas de incorporação recente ao processo produtivo. 
O crescimento da produção de soja fez com que a armazenagem a granel se tornasse prioritária à criação de programas de financiamentos resultará na injeção de grandes recursos por parte do Governo Federal. Entretanto, os programas especiais do governo, nem sempre têm continuidade garantida, dificultando o equilíbrio tão almejado entre a oferta e a demanda de serviços de armazenagem (Nogueira Junior e Tsunechiro, 2005).

Ainda assim, a expansão da produção justifica-se por diversos fatores, tais como o avanço tecnológico, as pesquisas agrícolas, disponibilidade de crédito rural e aumento das exportações. Esses itens permitiram melhoria no manejo da lavoura, maior eficiência do cultivo e, consequentemente maior produtividade (CONAB, 2016). Dependendo da região no Brasil, as perdas agrícolas podem atingir 20\%, ou mais, sendo ocasionadas, principalmente, pelo ataque de pragas devido à inadequação de instalações e à falta de conhecimentos técnicos (Weber, 2005).

Alguns estados do Brasil demonstram um quadro crítico em seus sistemas de armazenamento, como Mato Grosso e Paraná, que são os maiores produtores de soja e milho. Durante a safra, é notável o congestionamento nas estradas e, sobretudo, nos pátios de recepção das unidades armazenadoras, sendo comum o "armazenamento" da produção ao ar livre por falta de espaço nos silos. Para amenizar essa situação de déficit na armazenagem, cabe ponderar o escoamento rápido de parte da colheita. No entanto, é preciso também considerar que só uma parcela dos armazéns é destinada à recepção de grãos. Muitos deles ficam distantes e servem exclusivamente indústrias e portos. Soma-se a isso o fato de a concentração de barracões não corresponder ao volume produzido em cada região. Transportar grãos para regiões distantes de portos só encarece a produção, uma vez que o transporte também é um grave problema na estrutura do agronegócio brasileiro (Cicolin, 2016).

Contudo, o custo do sistema de armazenamento para soja e milho é semelhante, uma vez que a estrutura básica não é diferente. A estrutura básica para a armazenagem da soja é mais simples do que a estrutura para o milho, portanto, um pouco mais barata, pois devido a produtividade do milho ser maior que a da soja, há a necessidade da construção de mais silos armazenadores. Porém, é vantajosa a aquisição de um sistema completo, que possa permitir estocagem de ambos os produtos.
Para os pequenos e médios produtores, os benefícios provenientes da armazenagem em silos próprios são menores quando comparados aos benefícios gerados aos grandes produtores (Cristiano et al., 2016).

O perfeito conhecimento da matriz do custo operacional propicia a melhor definição de estratégias na otimização dos custos, uma vez que o tomador de decisões tem como determinar com precisão o impacto nos custos operacionais, relacionado à contratação de pessoal, consumo de energia elétrica e consumo de combustíveis utilizados nos secadores, custos administrativos, seguro, procedimentos operacionais e alteração de leiautes (Silva et al., 2006). Portanto, na elaboração de um projeto de implantação de uma unidade armazenadora de grãos devem ser considerados fatores técnicos e econômicos que viabilizem o empreendimento. $O$ projeto pode ser conveniente e adequado na concepção técnica, no entanto, poderá não ser economicamente viável, não retornando ao investidor a remuneração capaz de, no mínimo, pagar o investimento. Sendo assim, objetivou-se avaliar os custos e a viabilidade da implantação de uma unidade armazenadora de grãos no Mato Grosso.

\section{Material e Métodos}

O estudo foi realizado numa propriedade agrícola localizada em Sorriso, estado do Mato Grosso, em uma área de plantio de 1500 ha referente ao ano de 2016, com necessidade de instalação de uma unidade de beneficiamento e armazenamento de milho e soja. O estudo foi realizado para dez anos, sendo considerados anos com safras médias normais de soja e milho. A propriedade possui uma média de produtividade de 5,82 t ha ${ }^{-1}$ para milho e 3,33 $\mathrm{t} \mathrm{ha}^{-1}$ para soja. A capacidade diária máxima de colheita é de 500 t para o milho e 450 t para a soja.

A jornada de trabalho teve início às 7:00 h e finalizou às 18:00 $\mathrm{h}$, totalizando $11 \mathrm{~h}$ de recebimento. Para o processamento do produto na unidade armazenadora a jornada iniciou às 07:00 $\mathrm{h}$ e finalizou às 22:00 $\mathrm{h}$, totalizando $15 \mathrm{~h}$ de trabalho. Em época de recebimento e processamento, a unidade funcionou todos os dias da semana.

A Tabela 1 indica os resultados de produção esperada, tempo estimado de colheita e capacidade mensal de colheita para os produtos agrícolas milho safrinha e soja de acordo com os indicadores técnicos e as jornadas de trabalho da unidade.

Tabela 1. Produção esperada, tempo estimado de colheita e capacidade semanal de colheita de uma unidade produtora de grãos no Mato Grosso

\begin{tabular}{|c|c|c|c|c|c|c|}
\hline \multirow[t]{2}{*}{ Produto } & \multicolumn{2}{|r|}{ Produção esperada } & \multicolumn{2}{|c|}{ Tempo estimado de colheita } & \multicolumn{2}{|c|}{ Capacidade de Colheita } \\
\hline & $---\mathrm{t}---$ & -------- sacas 60 kg -------- & ----- dias ------ & ---- semanas ---- & ----- t dia-1 ------ & ----- sacas $\mathrm{dia}^{-1}$----- \\
\hline Milho & 8730 & 145500 & 17 & 2,5 & 500 & 8333 \\
\hline Soja & 5004 & 83400 & 11 & 1,6 & 450 & 7500 \\
\hline
\end{tabular}


A distribuição da quantidade de milho com os respectivos teores na colheita considerando a produção esperada e a quantidade colhida semanalmente pela propriedade agrícola estão apresentados na Tabela 2 .

Tabela 2. Distribuição da quantidade de milho colhido por semana com os respectivos teores de umidade em uma unidade produtora de grãos no Mato Grosso

\begin{tabular}{lcrrrr}
\hline \multirow{2}{*}{ Semana } & \multicolumn{3}{c}{ Teor de umidade na colheita $(\%)$} & \multirow{2}{*}{ Subtotal } \\
\cline { 2 - 5 } & \multicolumn{1}{c}{20} & 18 & 16 & 14 & \\
\hline \multirow{2}{*}{$1^{\text {a Semana }}$} & 1225 & 2275 & & & 3500 \\
$2^{\text {a Semana }}$ & & 1225 & 1400 & 875 & 3500 \\
$3^{\text {a Semana }}$ & & & 692 & 1038 & 1730 \\
Subtotal & 1225 & 3500 & 2092 & 1913 & 8730 \\
\hline Total $(\%)$ & 14,03 & 40,09 & 23,96 & 21,91 & 100 \\
\hline
\end{tabular}

O milho colhido, $14,03 \%$ apresentava com teor de umidade em torno de 20\% (Tabela 2). As quantidades colhidas de produtos durante as semanas de jornada de trabalho com as respectivas distribuições dos teores de umidade para o produto soja são apresentados na Tabela 3.

Tabela 3. Distribuição da quantidade de soja colhido por semana com os respectivos teores de umidade em uma unidade produtora de grãos no Mato Grosso

\begin{tabular}{lrrrr}
\hline \multirow{2}{*}{ Semana } & \multicolumn{2}{c}{ Teor de umidade na colheita $(\%)$} & \multirow{2}{*}{ Subtotal } \\
\cline { 2 - 4 } & \multicolumn{1}{c}{24} & 22 & 20 & \\
\hline \multirow{2}{*}{$1^{\text {a }}$ Semana } & 1102,5 & 1260,0 & 787,5 & 3150 \\
$2^{\text {a }}$ Semana & & 1112,4 & 741,6 & 1854 \\
Total & 1102,5 & 1260,0 & 787,5 & 5004 \\
\hline Total $(\%)$ & 22,0 & 25,2 & 15,7 & 100 \\
\hline
\end{tabular}

\section{Capacidade estática da unidade armazenadora}

As Tabelas 4 e 5 apresentam a distribuição de movimentação de produtos prevista ao longo do ano na unidade armazenadora. De acordo com a Tabela 4 e 5, observou-se que os meses de julho, agosto, setembro e outubro foram os que apresentam a previsão de maior estoque. Portanto, a capacidade estática da unidade foi de 5.230 toneladas. Há diferentes opções de montagem da estrutura de armazenamento, neste caso, a escolha foi de dois silos metálicos verticais de 3.000 toneladas cada, sendo um destinado ao armazenamento do milho e outro ao da soja.

Como a propriedade agrícola irá processar milho e soja, colhidos em períodos distintos, há necessidade de dimensionamento de somente uma linha de processamento que atenderá a demanda de toda a propriedade. Assim, deve ser dimensionada a unidade armazenadora considerando cada um dos produtos que serão processados, no entanto, os equipamentos escolhidos devem atender a maior demanda verificada no dimensionamento. A capacidade nominal calculada dos equipamentos foi arredondada para cima, de acordo com valores utilizados pelos fabricantes de equipamentos.

Tabela 4. Distribuição das previsões de entradas, saídas e estoques dos produtos de uma unidade armazenadora de grãos, em toneladas, no Mato Grosso para os meses de janeiro a junho de 2017

\begin{tabular}{|c|c|c|c|c|c|c|}
\hline & Jan & $\mathrm{Fev}$ & Mar & Abr & Maio & Jun \\
\hline \multirow{2}{*}{\multicolumn{7}{|c|}{ Milho }} \\
\hline & & & & & & \\
\hline $\begin{array}{l}\text { Estoque } \\
\text { anterior }\end{array}$ & 0 & 0 & 0 & 0 & 0 & 0 \\
\hline Entradas & 0 & 0 & 0 & 0 & 0 & 0 \\
\hline Saídas & 0 & 0 & 0 & 0 & 0 & 0 \\
\hline $\begin{array}{l}\text { Estoque } \\
\text { Atual }\end{array}$ & 0 & 0 & 0 & 0 & 0 & 0 \\
\hline \multicolumn{7}{|c|}{ Soja } \\
\hline $\begin{array}{l}\text { Estoque } \\
\text { anterior }\end{array}$ & 0 & 0 & 3004 & 0 & 0 & 3004 \\
\hline Entradas & 0 & 5004 & 0 & 0 & 0 & 0 \\
\hline Saídas & 0 & 2000 & 0 & 0 & 0 & 3004 \\
\hline $\begin{array}{l}\text { Estoque } \\
\text { Atual }\end{array}$ & 0 & 3004 & 3004 & 0 & 0 & 0 \\
\hline \multicolumn{7}{|c|}{ Total } \\
\hline $\begin{array}{l}\text { Estoque } \\
\text { anterior }\end{array}$ & 0 & 0 & 3004 & 0 & 0 & 3004 \\
\hline Entradas & 0 & 5004 & 0 & 0 & 0 & 0 \\
\hline Saídas & 0 & 2000 & 0 & 0 & 0 & 3004 \\
\hline $\begin{array}{l}\text { Estoque } \\
\text { Atual }\end{array}$ & 0 & 3004 & 3004 & 0 & 0 & 0 \\
\hline
\end{tabular}

\section{Dimensionamento do sistema de secagem}

Para o cálculo da capacidade efetiva de secagem foi necessário corrigir a capacidade nominal do secador em função do teor de umidade inicial e do produto a ser processado. A Tabela 6 apresenta os fatores de correção em função do teor de umidade inicial do produto.

\section{Secagem do milho}

$\mathrm{Na}$ primeira semana foram recebidas 1.225 toneladas de milho com 20\% de teor de umidade (Tabela 2). A capacidade nominal de secagem para o milho com $20 \%$ de umidade foi calculada através da eq. (1)

$$
\mathrm{CNS}=\frac{\mathrm{QPR}}{\mathrm{JDPxJT}}
$$

onde, CNS: capacidade nominal de secagem, $\mathrm{t} \mathrm{h}^{-1}$; QPR: quantidade de produto recebido, toneladas/semana ou mês; JDP: jornada diária de processamento, $\mathrm{h}$ dia $^{-1}$; JT: Jornada semanal ou mensal de trabalho, dia/semana ou mês. 
Tabela 5. Distribuição das previsões de entradas, saídas e estoques dos produtos de uma unidade armazenadora de grãos, em toneladas, no Mato Grosso para os meses de janeiro a junho de 2017

\begin{tabular}{|c|c|c|c|c|c|c|c|}
\hline & Jul & Ago & Set & Out & Nov & Dez & Totais \\
\hline \multicolumn{8}{|c|}{ Milho } \\
\hline Estoque anterior & 0 & 5230 & 5230 & 5230 & 5230 & 4230 & 25150 \\
\hline Entradas & 8730 & 0 & 0 & 0 & 0 & 0 & 8730 \\
\hline Saídas & 3500 & 0 & 0 & 0 & 1000 & 4230 & 8730 \\
\hline Estoque Atual & 5230 & 5230 & 5230 & 5230 & 4230 & 0 & 25150 \\
\hline \multicolumn{8}{|c|}{ Soja } \\
\hline Estoque anterior & 0 & 0 & 0 & 0 & 0 & 0 & 6008 \\
\hline Entradas & 0 & 0 & 0 & 0 & 0 & 0 & 5004 \\
\hline Saídas & 0 & 0 & 0 & 0 & 0 & 0 & 5004 \\
\hline Estoque Atual & 0 & 0 & 0 & 0 & 0 & 0 & 6008 \\
\hline \multicolumn{8}{|c|}{ Total } \\
\hline Estoque anterior & 0 & 5230 & 5230 & 5230 & 5230 & 4230 & 31158 \\
\hline Entradas & 8730 & 0 & 0 & 0 & 0 & 0 & 13734 \\
\hline Saídas & 3500 & 0 & 0 & 0 & 1000 & 4230 & 13734 \\
\hline Estoque Atual & 5230 & 5230 & 5230 & 5230 & 4230 & 0 & 31158 \\
\hline
\end{tabular}

Tabela 6. Fator de correção em função do teor de umidade inicial do produto (teor de umidade final de referência de 13\%) em uma unidade armazenadora de grãos no Mato Grosso

\begin{tabular}{lcccccc}
\hline & \multicolumn{6}{c}{ Teor de umidade inicial $(\%)$} \\
\cline { 2 - 7 } & 24 & 22 & 20 & 18 & 16 & 14 \\
\hline $\begin{array}{l}\text { Fator de } \\
\begin{array}{l}\text { Correção da } \\
\text { umidade }\left(\mathrm{f}_{\mathrm{u}}\right)\end{array}\end{array}$ & 0,480 & 0,582 & 0,746 & 1,000 & 1,470 & 2,700 \\
\hline
\end{tabular}

Fonte: Weber (2001)

A capacidade efetiva de secagem de um secador com capacidade nominal de 11,67 $\mathrm{t} \mathrm{h}^{-1}$, utilizado para a secagem de milho de $20 \%$ para $13 \%$ foi calculada através da eq. 2 :

$$
\mathrm{CES}=\mathrm{CNS} \times \text { fu } \times \mathrm{f} \varrho
$$

onde, CES: capacidade efetiva de secagem, $\mathrm{t} \mathrm{h}^{-1}$ fu: fator de correção para umidade inicial; fe fator de correção para o milho.

A capacidade de processamento necessária foi de $11,67 \mathrm{t} \mathrm{h}^{-1}$, porém como a umidade do milho foi de $20 \%$, a capacidade efetiva de secagem do secador foi de 6,53 $\mathrm{t} \mathrm{h}^{-1}$ Portanto, para atender a demanda de 11,67 $\mathrm{t} \mathrm{h}^{-1}$, o secador deve apresentar a seguinte capacidade nominal corrigida pela eq. 3 :

$$
\mathrm{CNSC}=\frac{\mathrm{CNS}}{\mathrm{CES}} \times \mathrm{CNS}
$$

onde, CNSC: capacidade nominal de secagem corrigida, $\mathrm{t} \mathrm{h}^{-1}$
Isso significa que um secador, cuja capacidade nominal de 20,85 $\mathrm{t} \mathrm{h}^{-1}$ apresentou uma capacidade efetiva de secagem de $16,25 \mathrm{t} \mathrm{h}^{-1}$ no processamento de milho com $20 \%$ de teor de umidade inicial.

A primeira semana da safra de soja foi a que apresentou a maior demanda de secagem. Como não houve secagem de dois ou mais produtos concomitantemente, houve a necessidade de somente um secador para atendimento no processo de secagem. Portanto, o secador deve ser escolhido em função da maior demanda, ou seja, $52,55 \mathrm{th}^{-1}$.

\section{Dimensionamento do sistema de limpeza}

No dimensionamento do sistema de limpeza de grãos é conveniente que a unidade armazenadora tenha um sistema de máquina de pré-limpeza para processamento antes da secagem para a retirada de impurezas (pó, torrões de terra, vagem, sabugos, palha, etc).

Para a obtenção da capacidade efetiva ou real das máquinas de pré-limpeza deve-se corrigir a capacidade nominal em função do tipo de máquina, da capacidade nominal do equipamento e da massa específica do produto. Considerando o dimensionamento do secador de grãos, foi escolhida uma máquina de pré-limpeza com a capacidade igual ou superior a capacidade do secador em função da possibilidade de processar produto de forma contínua.

\section{Dimensionamento do silo pulmão}

A capacidade do silo pulmão deve ser suficiente para armazenar uma quantidade de produto visando atender a diferença de tempo entre as jornadas de processamento e de recebimento, considerando ainda a capacidade de 
secagem pré-estabelecida. A presença do silo pulmão é uma garantia da manutenção da qualidade do produto, visto que o mesmo não permanecerá estocado na moega aguardando ser processado. A capacidade estática mínima do silo pulmão foi calculada pela eq. (4).

$$
\mathrm{CSP}=\mathrm{CS} \times(\text { JDP-JDR) }
$$

onde, CSP: capacidade estática total dos silos pulmões, t; CS: capacidade de secagem, $\mathrm{t} \mathrm{h}^{-1}$; JDP: jornada diária de processamento, $\mathrm{h}$ dia $^{-1}$; JDR: jornada diária de recebimento, $\mathrm{h} \mathrm{dia}^{-1}$

\section{Dimensionamento dos transportadores}

Transportador da moega para a máquina de pré-limpeza

O sistema de transporte da moega para as máquinas de pré-limpeza deve ter uma capacidade suficiente para que durante a jornada de recebimento possa atender a linha de secagem, de acordo com a eq. (5).

$$
\mathrm{CNT}=\frac{(10 \times \mathrm{CNS})+\mathrm{CSP}}{10}
$$

onde, CNT: capacidade nominal do transportador, $\mathrm{t}$ $\mathrm{h}^{-1}$; CNS: capacidade nominal do secador, $\mathrm{t} \mathrm{h}^{-1}$; CSP: capacidade estática do silo pulmão, $\mathrm{t}$

Transportador da máquina de pré-limpeza ao secador ou silo pulmão

A capacidade do transportador deve ser de 10 a $20 \%$ acima da capacidade nominal do equipamento que o alimenta (eq. 6):

$$
\mathrm{CT}=\frac{\mathrm{CNE}}{0,9}
$$

onde, CT: capacidade efetiva ou real do transportador, $\mathrm{t}$ $\mathrm{h}^{-1}$; CNE: capacidade nominal do equipamento, $\mathrm{t}^{-1}$

\section{Transportador do silo pulmão ao secador}

Para o transporte do silo pulmão até o secador foi utilizado o mesmo transportador responsável pelo transporte da máquina de pré-limpeza até o secador/silo pulmão.

\section{Transportador do secador ao silo}

Para o transporte do secador até aos silos de armazenamento foi utilizado um transportador com capacidade nominal superior a capacidade nominal do secador.

\section{Transportador do silo armazenador para o silo expedição}

Para o transporte do silo armazenador para o silo expedição foi utilizado um transportador com capacidade nominal de $80 \mathrm{t} \mathrm{h}^{-1}$, considerando uma cadência média de carga de três caminhões de aproximadamente 25 t de carga cada.

\section{Avaliação da rentabilidade do capital investido}

Para a avaliação da rentabilidade do projeto não foi levado em consideração os impostos que devem ser pagos ao estado.

\section{Valor presente líquido}

O Valor Presente Líquido [VPL] define a viabilidade do projeto. Através da eq. (7) determinou o valor presente de pagamentos futuros descontados a uma taxa de juros apropriada, menos o custo do investimento inicial (Hoffmann et al., 1987).

$$
\mathrm{VPL}=\mathrm{Fc}_{0}+\frac{\mathrm{Fc}_{1}}{(1+\mathrm{TMA})^{1}}+\frac{\mathrm{Fc}_{2}}{(1+\mathrm{TMA})^{2}}+\ldots+\frac{\mathrm{Fcn}}{(1+\mathrm{TMA})^{\mathrm{n}}}
$$

onde, $\mathrm{Fc}_{0}$ : fluxo de caixa no período zero, $\mathrm{R} \$ ; \mathrm{Fc}_{1}$ : fluxo de caixa em determinado período, R\$; TMA: Taxa mínima de atratividade, $\%$

Para o cálculo do VPL foi utilizado uma taxa de juros de 8,5\%, baseada no Programa para Construção e Ampliação de Armazéns [PCA] do governo federal, que possui carência de até 3 anos e até 15 anos para a quitação do financiamento.

\section{Taxa interna de retorno [TIR]}

A Taxa Interna de Retorno [TIR] iguala o VPL a zero, ou seja, é a taxa que iguala o valor presente das saídas ao valor presente das entradas de caixa de um projeto (Bisognin; Aragão, 2014). Calculada a partir da eq. 8.

$$
\mathrm{VPL}=0=\mathrm{Ii}+\frac{\mathrm{Ft}}{(1+\mathrm{TIR})^{\mathrm{t}}}
$$

onde, VPL: valor presente líquido, R\$; Ii: Investimento inicial, R\$; Ft: Fluxo de caixa no período, R\$; TIR: taxa interna de retorno, anos

\section{Payback}

O payback [PB] representa o tempo, em meses ou anos, necessário para se recuperar o capital investido, ou seja, quanto tempo levará para retornar o dinheiro investido no projeto (Vergara et al., 2016). Calculado a partir da eq. 9.

$$
\operatorname{VPfcp}=\mathrm{Fc} 0+\frac{\mathrm{Fcp}_{\mathrm{cP}}}{(1+\mathrm{TMA})^{\mathrm{P}}}
$$

onde, VPfcp: valor presente do fluxo de caixa no período, $\mathrm{R} \$ ; \mathrm{Fc}_{0}$ : fluxo de caixa no período inicial, $\mathrm{R} \$$; Fcp: fluxo de caixa no período, R\$; TMA: taxa mínima de atratividade, $\%$

\section{Ponto de equilíbrio econômico}

O Ponto de Equilibrio Econômico [PEE] mostra a partir de quantas unidades vendidas a empresa passa a ser lucrativa. É o ponto em que os produtos vendidos pagam todos os custos e despesas (fixas e variáveis), e ainda não se obtém lucro. Calculado através da eq. 10 . 


$$
\mathrm{PEE}=\frac{(\mathrm{Cf}+\mathrm{Df})}{\mathrm{Mc}}
$$

onde: Cf: Custo fixo, R\$; Df: Despesa fixa, R\$; Mc: Margem de contribuição, $\mathrm{R} \$$

\section{Resultados e Discussão}

A Tabela 7 apresenta o resumo dos equipamentos dimensionados e suas respectivas capacidades nominais, este dimensionamento foi feito de acordo com a necessidade do produtor.

Tabela 7. Resumo de equipamentos e respectivas capacidades em uma unidade armazenadora de grãos no Mato Grosso

\begin{tabular}{lccr}
\hline \multicolumn{1}{c}{ Equipamento } & Unidade & Quantidade & Capacidade Nominal \\
\hline Máquina de pré-limpeza & $\mathrm{t} \mathrm{h}^{-1}$ & 1 & 120 \\
Secador & $\mathrm{t} \mathrm{h}^{-1}$ & 1 & 80 \\
Silo pulmão & $\mathrm{t}$ & 1 & 300 \\
Silo armazenador & $\mathrm{t}$ & 2 & 3000 \\
Transportador (moega x pré-limpeza) & $\mathrm{t} \mathrm{h}^{-1}$ & 1 & 80 \\
Transportador (pré-limpeza x secador) & $\mathrm{t} \mathrm{h}^{-1}$ & 1 & 80 \\
Transportador (secador x silo) & $\mathrm{t} \mathrm{h}^{-1}$ & 1 & 80 \\
Transportador (silo x expedição) & $\mathrm{t} \mathrm{h}^{-1}$ & 1 & 80 \\
\hline
\end{tabular}

\section{Custos da obra e equipamentos}

Foi solicitado um orçamento completo (valores da estrutura, montagem, frete dos equipamentos, construção da parte civil e instalações elétricas) dos equipamentos dimensionados, para uma empresa de grande porte do setor de armazenagem (Tabela 8).

$\mathrm{Na}$ Tabela 9 estão dispostos os preços dos serviços complementares para o projeto, como, frete dos equipamentos, construção civil, montagem dos equipamentos e montagem elétrica, totalizando um valor de $\mathrm{R} \$ 2.257 .764,96$.

Na Tabela 10 obteve-se o valor total da obra (Tabelas 8 e 9), acrescido de $10 \%$ para eventuais necessidades não programadas, como a adequação da estrutura, aquisição de equipamentos de classificação, computadores, balança rodoviária, estação meteorológica, licença ambiental e de operação.

Tabela 8. Resumo de valores dos equipamentos e serviços para a construção de uma unidade armazenadora de grãos no Mato Grosso

\begin{tabular}{|c|c|c|c|c|}
\hline Item & Modelo & Quantidade & Valor & Subtotal \\
\hline & & & \multicolumn{2}{|c|}{-----o- } \\
\hline Máquina de pé Limpeza & MPL080 & 1 & $86.203,09$ & $86.203,09$ \\
\hline Secador de grãos & SCC60 & 1 & $305.740,00$ & $305.740,00$ \\
\hline Silo pulmão & SP300 & 1 & $112.732,13$ & $112.732,13$ \\
\hline Silo armazenador & SAG6012 & 2 & $249.955,79$ & $499.911,58$ \\
\hline Silo expedição & SEXP1204 & 1 & $25.443,77$ & $25.443,77$ \\
\hline Transportador de corrente (14 m) & TCR080 & 1 & $15.432,48$ & $15.432,48$ \\
\hline Transportador de corrente $(15 \mathrm{~m})$ & TCR080 & 1 & $16.534,80$ & $16.534,80$ \\
\hline Correia transportadora $(32 \mathrm{~m})$ & CT120 & 1 & $30.061,76$ & $30.061,76$ \\
\hline Correia transportadora $(50 \mathrm{~m})$ & CT120 & 1 & $46.971,50$ & $46.971,50$ \\
\hline Elevador de canecas (24 m) & EL080 & 1 & $32.780,26$ & $32.780,26$ \\
\hline Elevador de canecas (40 m) & EL080 & 2 & $54.633,76$ & $109.267,52$ \\
\hline Elevador de canecas $(46 \mathrm{~m})$ & EL080 & 1 & $62.828,83$ & $62.828,83$ \\
\hline Tubulação e estaiamento & - & 1 & $67.195,39$ & $67.195,39$ \\
\hline Total & & & & $1.411 .103,11$ \\
\hline
\end{tabular}


Tabela 9. Valores dos serviços para a construção de uma unidade armazenadora de grãos no Mato Grosso

\begin{tabular}{lr}
\hline \multicolumn{1}{c}{ Serviços } & \multicolumn{1}{c}{ Subtotal } \\
\hline & - \\
Frete dos equipamentos & $155.221,34$ \\
Construção civil & $1.552 .213,42$ \\
Montagem dos equipamentos & $380.997,83$ \\
Montagem elétrica & $169.332,37$ \\
\hline Total & $2.257 .764,96$ \\
\hline
\end{tabular}

Tabela 10. Resumo de valores para a construção de uma unidade armazenadora de grãos no Mato Grosso

\begin{tabular}{lr}
\hline \multicolumn{1}{c}{ Serviços } & \multicolumn{1}{c}{ Subtotal } \\
\hline & ------------ R\$ \\
Equipamentos & $1.411 .103,11$ \\
Serviços & $2.257 .764,96$ \\
Sobra $10 \%$ & $366.886,81$ \\
\hline Total & $4.035 .754,88$ \\
\hline
\end{tabular}

\section{Custos Variáveis}

Para calcular os custos variáveis do projeto, foram considerados os gastos com energia elétrica e mão de obra durante 56 dias referentes a 28 dias de recebimento e 28 dias de expedição do produto, seguro de armazenamento e lenha para secagem. Como referência de custos do produto, para gastos com energia elétrica foram utilizados $\mathrm{R} \$ 0,20$ por saca de grãos processados, para a mão de obra foram utilizados $\mathrm{R} \$ 0,40$ por saca, para o seguro de armazenagem, foi adotado o valor de $\mathrm{R} \$ 0,15$ por saca e para a lenha utilizada na secagem, $\mathrm{R} \$ 0,32$ por saca. Estes custos foram levantados com produtores da região (Tabela 11).

Tabela 11. Custo Variável Anual para a construção de uma unidade armazenadora de grãos no Mato Grosso

\begin{tabular}{lr}
\hline \multicolumn{1}{c}{ Item } & \multicolumn{1}{c}{ Subtotal } \\
\hline & ------- \\
Energia Elétrica & $44.597,92$ \\
Mão de Obra & $92.000,00$ \\
Seguro Armazenamento & $34.335,00$ \\
Lenha & $73.500,00$ \\
\hline Total & $244.432,92$ \\
\hline
\end{tabular}

\section{Custos Fixos}

Para o cálculo do custo fixo foi considerado o gasto com manutenção e seguro dos equipamentos e depreciação da unidade. Tomaram-se por base algumas referências de custos do produto. Para a manutenção dos equipamentos e seguro, foi calculado o valor de $10 \%$ do valor total do investimento e para a depreciação foi adotado um valor de $5 \%$ e arredondado para $\mathrm{R} \$$ 200.000,00 para facilitar os cálculos (Tabela 12).

Tabela 12. Custo Fixo Anual para a construção de uma unidade armazenadora de grãos no Mato Grosso

\begin{tabular}{lr}
\hline \multicolumn{1}{c}{ Item } & \multicolumn{1}{c}{ Subtotal } \\
\hline & ------- $\mathrm{R} \$$------- \\
Manutenção equipamento & $40.352,54$ \\
Seguro equipamento & $40.352,54$ \\
Depreciação total & $200.000,00$ \\
\hline Total & $280.705,08$ \\
\hline
\end{tabular}

Orçamento da receita bruta

A base do cálculo da receita bruta foi o valor agregado ao produto que foi beneficiado e a diferença com o produto não beneficiado. Os valores tomados como base foram levantados com produtores da região do norte do estado do Mato Grosso, onde se utiliza um valor de $\mathrm{R} \$ 83,30$ por tonelada (soja e milho).

Considerando os dados de produtividade da Tabela 1, a receita bruta anual do projeto foi de $\mathrm{R} \$ 416.833,20$ para o soja e $\mathrm{R} \$ 727.209,00$ para o milho, totalizando $\mathrm{R} \$ 1.144 .042,20$ de receita anual.

\section{Avaliação econômica do projeto}

De acordo com os dados da Tabela 13, do ponto de vista econômico, o projeto apresentou-se satisfatório, onde em todos os anos obteve-se uma renda líquida

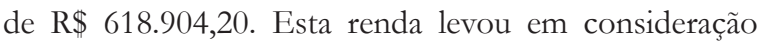
condições normais de produtividade e colheita, com produtividade de 97 sacas de milho por hectare e 55,6 sacas de soja por hectare.

Analisando a Tabela 13, o fluxo econômico em 10 anos totaliza R\$ 6.189.042,00. Esse valor descontado do valor total do investimento $(\mathrm{R} \$ 4.035 .754,88)$ descrito na Tabela 10 resulta em um fluxo financeiro de $\mathrm{R} \$$ 2.153.288,12. Com base nessas informações e utilizando o cálculo do "Payback" descontado, pode-se afirmar que o capital investido será recuperado entre 9 e 10 anos conforme apresentado na Tabela 14.

O VPL demonstrou que, com a atualização do fluxo econômico do projeto a uma taxa de $8,5 \%$ do financiamento, obteve um saldo positivo de $\mathrm{R} \$ 25.090,99$ no final de 10 anos. Trindade et al. (2013) analisaram a viabilidade de implantação de uma unidade armazenadora na cidade de Capão Bonito, SP e verificaram que o valor do investimento inicial foi de $\mathrm{R} \$ 379.220,55$ e o valor presente líquido foi de $\mathrm{R} \$ 87.377,06$. 
Tabela 13. Avaliação econômica da construção de uma unidade armazenadora de grãos no Mato Grosso

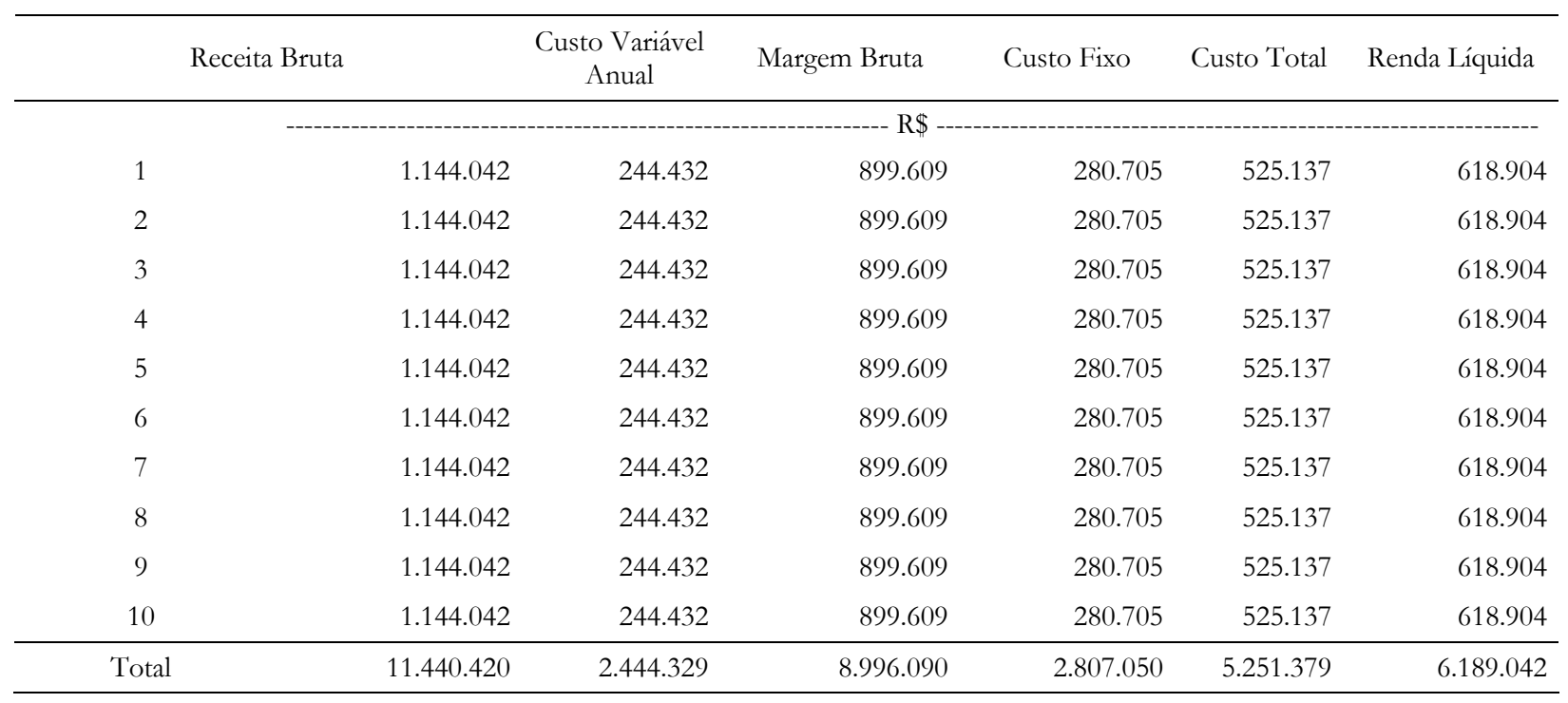

Tabela 14. Avaliação econômica do projeto

\begin{tabular}{crr}
\hline Ano & \multicolumn{1}{c}{ Renda Líquida } & \multicolumn{1}{c}{ "Payback" } \\
\hline 0 & $-4.035 .754,88$ & $-4.035 .754,88$ \\
1 & $618.904,20$ & $-3.465 .336,26$ \\
2 & $618.904,20$ & $-2.939 .604,82$ \\
3 & $618.904,20$ & $-2.455 .059,71$ \\
4 & $618.904,20$ & $-2.008 .474,35$ \\
5 & $618.904,20$ & $-1.596 .874,95$ \\
6 & $618.904,20$ & $-1.217 .520,66$ \\
7 & $618.904,20$ & $-867.885,36$ \\
8 & $618.904,20$ & $-545.640,86$ \\
9 & $618.904,20$ & $-248.641,31$ \\
10 & $618.904,20$ & $25.090,99$ \\
\hline
\end{tabular}

A TIR calculada para este projeto foi de $6,98 \%$ ao ano, indicando uma rentabilidade baixa do capital investido, tomando como parâmetro taxa de juros de 10,15\% ao ano (Banco Central, 2017). Gottardo e Cestari Junior (2008) realizaram um estudo de viabilidade econômica para implantação de uma unidade armazenadora na cidade de Campo Mourão, PR o observaram um investimento inicial de $\mathrm{R} \$ 598.813,04$, resultando em uma taxa interna de retorno de $13,06 \%$.

O PEE foi de R $\$ 356.224,72$ ou 71.245 sacas beneficiadas e comercializadas no ano para que a unidade tenha todos os seus custos de operação pagos, e a partir daí comece a gerar lucro, foi considerado o valor do lucro da saca de milho sendo o mesmo da saca de soja, $\mathrm{R} \$ 5,00$ livre de impostos.
Em um estudo de viabilidade econômica para um silo secador de capacidade de 320 toneladas de soja ou milho em Nova Cantu, PR, no ano de 2016, o qual foi orçado em R \$420.618,20, Pereira e Oliveira (2016) concluíram que o resultado do investimento foi favorável. Tais custos refletiram em menor valor por saca armazenada (R\$ 1,31) que o presente estudo, variação devido à projetos de empresas diferentes, custos variáveis de cada município, tamanho do projeto e produtividade da área estudada.

Da mesma forma, Vergara et al. (2016) realizaram um orçamento para construção de armazém, e citaram que para atender melhor a demanda do produtor rural, foi adotado o sistema de armazenagem com 2 silos verticais, assim como neste trabalho, para otimizar a operação e possibilitar ao produtor o armazenamento de dois produtos diferentes ao mesmo tempo.

As principais vantagens da instalação de uma unidade armazenadora são: condições para negociar a produção no momento mais apropriado, redução de custos com fretes, eliminação de despesas de pré-limpeza, limpeza, secagem e armazenagem, aproveitamento de subprodutos e redução das dificuldades na negociação da safra, além possibilitar oferecimento de serviços de secagem de grãos a terceiros (Santos e Centenaro, 2014).

Se a armazenagem for utilizada de forma adequada, pode se constituir em uma grande vantagem competitiva, pois o produto poderá ser vendido na entressafra, época em que o preço de venda do milho e soja aumenta significativamente, uma vez que é mais viável ao produtor rural manter sua produção armazenada em sua própria fazenda, devido ao alto valor cobrado para armazenagem por empresas em Sorriso, MT, haja vista que para um período de quatro meses o produtor gastaria $R \$ 0,84$ por 
saca para armazenar seu produto em seu próprio sistema de armazenagem ao passo que esse preço subiria para $\mathrm{R} \$ 1,74$ por saca utilizando o serviço de uma empresa do município para armazenar a mesma quantidade de produto (Dambrosio, 2009).

Assim, verificar os custos de implantação de uma unidade armazenadora de grãos é importante, porém é preciso realizar um estudo de viabilidade econômica para o produtor saber se o projeto é viável na propriedade. Isso é importante para saber quais investimentos/projetos se tornam viáveis financeiramente àquela fazenda.

\section{Conclusão}

O custo total para a construção de duas unidades armazenadoras de grãos (3000 toneladas cada) no Mato Grosso é de R \$ 4.035.754,88 contra uma renda liquida de $\mathrm{R} \$$ 6.189.042 para os primeiros 10 anos de atividade. Assim, a sua construção é viável economicamente, pois o retorno do capital investido é considerado de curto prazo, haja vista que os equipamentos terão vida útil de até 20 anos.

A quantidade de grãos beneficiados ultrapassa a quantidade mínima calculada para ponto de equilíbrio econômico, gerando lucro para o produtor.

Este trabalho não considerou cenários com variações de produtividade e preços, tornando mais robusta a análise de viabilidade econômica, o estudo com variações de cenários pode ser um potencial estudo futuro.

\section{Referências}

Banco Central do Brasil [BCB]. 2017. Dados diários. Disponível em: http://www.bcb.gov.br/htms/selic/selicdiarios.asp Acesso em: 15 jun. 2017.

Bisognin L.F; Aragão T.R. de P. 2014. Viabilidade econômica da implantação de uma unidade de abate e processamento de suínos. Revista iPecege 1(1): 51-62.

Cicolin L.O.M; Oliveira A.L.R. 2016. Avaliação de desempenho do processo logístico de exportação do milho brasileiro: uma aplicação da análise envoltória de dados - DEA. Journal of Transport Literature 10(3): 30-34.

Companhia Nacional de Abastecimento [CONAB]. 2016. Evolução dos custos de produção de soja no Brasil 2016. Disponível em: <http://www.conab.gov.br/OlalaCMS/ uploads/arquivos/16_09_06_14_17_57_compendio_de_ estudos_conab_-_volume_2,_2016.pdf> Acesso em: 11 set. 2016.

Cristiano A.C.; Rodrigues F.S.; Souza J.P. 2016. Viabilidade econômica do armazenamento de soja na propriedade rural: Vantagem Competitiva via redução de despesas e benefícios para a Estratégia de Comercialização. Revista Análise Econômica 24(45): 141-160.

Dambrosio M.A.; Redivo A.; Redivo A.R.; Ferreira G. A. 2009. Custos da padronização e armazenagem da soja em armazém próprio no município de Sorriso/MT. Revista Contabilidade \& Amazônia 2(1): 118-133.

Gottardo, F.A; Cestari. H.J. 2008. Viabilidade econômico- financeira de implantação de um sistema de armazenagem de grãos: um estudo de caso em uma média propriedade rural em Campo Mourão - PR. Revista em Agronegócios e Meio Ambiente 1(1): 55-76.

Hoffmann, R.; Serrano, O.; Neves, E.M.; Thame, A.C. de M.; Engler, J.J. de C. 1987. Administração da empresa agrícola. 5. ed. São Paulo: Pioneira Estudos Agrícolas, 325p.

Noqueira Junior S.; Tsunechiro A. 2005. Produção Agrícola e infraestrutura de armazenagem no Brasil. Informações Econômicas 35(2): 8-18.

Pereira L.F.R; Oliveira V. 2016. Viabilidade econômica para implantação de uma unidade armazenadora de grãos em uma propriedade no município de Nova Cantu - PR. Revista Cultivando o Saber, edição especial: 81-91.

Santos D.L.; Centenaro M. 2014. Análise do sistema de armazenamento de soja: Próprio X Terceirizado. $8^{\circ} \mathrm{UNEPE}$ UFGD e $5^{\circ}$ EPEX UEMS - Universidade Estadual do Mato Grosso do Sul, n.6.

Silva L.C.; Queiroz D.M.; Flores R.A. 2006. Estimativa de Custos operacionais em unidades armazenadoras de grãos por meio de simulação. Revista Brasileira de Armazenamento 31(1): 1-7.

Silveira L.S.; Melo M.S. 2006. Automação da armazenagem: o caso da multi distribuidora. Disponível em: XIII SIMPEP Universidade Estadual de São Paulo

Silva L.C. 2005. Unidades Armazenadoras. Planejamento e Gerenciamento Otimizado. Revista Cultivar Máquinas 44: ano III.

Trindade V.R.; Amaral L.P.E.; Sacco S.R.; Entelmann F.A. 2013. Plano de Negócio: Viabilidade Econômica Para Implantação de uma Unidade de Armazenamento e Beneficiamento de Grãos, no Município de Capão Bonito - SP. Anais do Simpósio Nacional de Tecnologia em Agronegócio Faculdade de Tecnologia de Ourinhos.

Vergara W.R.H.; Oliveira J.P.C.; Barbosa F.A.; Yamanari J.S. 2016. Análise de viabilidade econômico-financeira para aquisição de uma unidade de armazenagem de soja e milho. Revista Gepros 12(1): 41-61.

Weber, E.A., 2001. Armazenagem Agrícola. Livraria e Editora Agropecuária, Guaíba: RS.

Weber, E.A. 2005. Excelência em beneficiamento e armazenagem de grãos. Canoas: Salles. 